\title{
Surgical Techniques \\ for Conjunctival and Corneal \\ Tumors
}

\author{
Raksha Rao and Carol L. Shields
}

\section{Surgical Management}

A thorough examination with documentation of the clinical findings and systematic planning is a prerequisite to any surgery. Clinical examination by penlight and slit-lamp biomicroscopy helps determine the extent of the tumor. Careful inspection of the entire conjunctiva with lid eversion should be performed. Conjunctival nevus, primary acquired melanosis (PAM), or melanoma sometimes has amelanotic component which should be noted. A large drawing of the conjunctival tumor replicating the extent of the lesion in the eye is used in all cases in the office and at the time of surgery. The drawing should include the extent of corneal involvement and the surgical plan.

In general, management alternatives include surgical excision, topical or injection chemotherapy or immunotherapy, radiotherapy, chemotherapy, or targeted medications such as rituximab.

Electronic supplementary material The online version of this chapter (https://doi.org/10.1007/978-3-030-18757$\left.6 \_7\right)$ contains supplementary material, which is available to authorized users.

R. Rao $(\bowtie)$

Department of Orbit and Ophthalmic Oncology,

Narayana Nethralaya, Bangalore, India

C. L. Shields

Ocular Oncology Service, Wills Eye Hospital,

Thomas Jefferson University, Philadelphia, PA, USA
Tumors that come to surgical excision include malignant tumors and some symptomatic benign tumors. Complete excisional biopsy using the traditional "no-touch" technique is advised. The "no touch" technique involves tumor removal without directly touching the mass and only manipulating the surrounding normal tissue as well as the avoidance of balanced salt solution (BSS) for corneal wetting as this also can lead to tumor dissemination. So the entire procedure is performed under dry circumstances and without touching the tumor directly. This is especially important for conjunctival melanoma as it can easily seed into the subconjunctival space and demonstrate recurrence after surgery. Incisional surgery and frozen sections are not often used. However, there are certain exceptions in which incisional biopsy might be considered (Table 7.1).

For papillomas, excisional biopsy and cryotherapy using the "no touch" technique with or without adjuvant oral cimetidine and/or topi$\mathrm{cal} /$ injection interferon alfa- $2 \mathrm{~b}$ provides satisfactory tumor control [1]. For conjunctival intraepithelial neoplasia (CIN) and invasive squamous cell carcinoma (SCC), surgical excision can be performed especially if there is a need to quickly manage the patient, if there are dexterity problems in which the patient cannot place therapeutic eyedrops, or if there is concern about compliance. In such cases, complete surgical excision of SCC using the "no touch" technique is employed. However, with CIN and 
Table 7.1 Indications for surgery or topical therapy for conjunctival tumors

\begin{tabular}{|c|c|c|}
\hline $\begin{array}{l}\text { Conjunctival } \\
\text { tumor }\end{array}$ & Indication for excisional surgery & Indication for other treatments \\
\hline $\mathrm{CIN} / \mathrm{SCC}$ & Large, well-circumscribed tumor & $\begin{array}{l}\text { Topical chemotherapy or immunotherapy } \\
\text { Small tumor } \\
\text { Large tumor for chemoreduction or } \\
\text { immunoreduction before surgery } \\
\text { Diffuse tumor not amenable to surgery } \\
\text { Positive margins post-excision } \\
\text { Plaque radiotherapy } \\
\text { Multiple recurrences } \\
\text { Scleroinvasive tumors } \\
\text { Incisional surgery and possible exenteration } \\
\text { Tumor invasion into orbit }\end{array}$ \\
\hline Nevus & $\begin{array}{l}\text { Documented growth } \\
\text { Atypical location (fornix, palpebral } \\
\text { conjunctiva, cornea) } \\
\text { Atypical age at presentation (middle age or } \\
\text { later) } \\
\text { Positive family history of conjunctival } \\
\text { melanoma } \\
\text { Patient insistence (cosmesis) }\end{array}$ & $\begin{array}{l}\text { Observation } \\
\text { Small, typical nevus }\end{array}$ \\
\hline PAM & $\begin{array}{l}\text { Lesion diameter } \geq 5 \mathrm{~mm} \\
\text { Documented progression of the lesion } \\
\text { Thickness of the lesion } \\
\text { Distinct nodule arising within the lesion } \\
\text { (pigmented or non-pigmented) } \\
\text { Nutrient vessels to the lesion } \\
\text { Involvement of the cornea } \\
\text { Involvement of palpebral conjunctiva } \\
\text { Dysplastic nevus syndrome in the affected } \\
\text { patient or close relatives } \\
\text { Personal history of cutaneous or uveal } \\
\text { melanoma }\end{array}$ & $\begin{array}{l}\text { Observation } \\
\quad \text { Lesion diameter }<5 \mathrm{~mm}\end{array}$ \\
\hline Melanoma & $\begin{array}{l}\text { All cases except where exenteration is } \\
\text { necessary }\end{array}$ & $\begin{array}{l}\text { Incisional surgery and possible exenteration } \\
\text { Orbital extension }\end{array}$ \\
\hline
\end{tabular}

SCC, topical chemotherapy (mitomycin-C and 5-flurouracil) and topical immunotherapy (topical or injection interferon alpha-2b) are alternatives to surgical resection for reliable patients, dexterous in placing eyedrops, for small tumors and for large tumors, especially important for the elderly or sickly patient not amenable to surgical procedures.

For malignancies that invade into the sclera, local plaque radiotherapy is performed to irradiate the invasive area and prevent intraocular growth. For SCC an apex dose of $4500 \mathrm{cGy}$ is given and for melanoma the dose is $6000 \mathrm{cGy}$. Plaque radiotherapy is particularly useful for those with multiple recurrences, in an effort to avoid orbital exenteration and other mutilating surgeries [2, 3].

Exenteration is reserved for advanced cases with clinical and radiological evidence of orbital invasion. In general, we use the eyelid sparing technique in which incision is made just outside the eyelash margin so that the posterior lamella is dissected up to the orbital rim, sparing the anterior lamella (skin and orbicularis muscle). The orbit is dissected and removed.

Special consideration is given to the management of conjunctival nevus and PAM. Conjunctival nevus can be managed by peri- 
odic observation with photographic documentation or surgical resection, depending on tumor size, symptoms, features, and parental concerns [4]. For most children with conjunctival nevus, observation is provided and the tumor is surgically removed when the patient is older, in the late teenage years. If growth is found, excision is advised. Prompt surgery for conjunctival nevus is considered in those presenting at atypical sites (fornix, palpebral conjunctiva, cornea), at an older age, in patients with family history of conjunctival or cutaneous melanoma, and in large nevus causing cosmetic blemish [4].

Newly discovered PAM which is flat and measures $<5 \mathrm{~mm}$ in a patient without dysplastic nevus syndrome or cutaneous melanoma can be observed [5]. However, if the lesion shows growth, multifocality, or asymmetry compared to the opposite eye, or measuring $\geq 5 \mathrm{~mm}$ ( $>2$ clock hours), surgery is indicated [5]. If PAM demonstrates even minimal nodulatity, melanoma is suspected and surgical removal is advised. Conjunctival melanoma is a surgical disease and all cases require careful removal of the entire lesion with negative margins [6].

Each tumor is managed in a slightly different way. Conjunctival choristoma is managed by superficial shaving or deeper excision with lamellar sclerectomy and keratectomy [7]. For papillomas, a meticulous "no touch" technique is employed and pedunculated tumors are excised at the base and additional interferon is considered [1]. CIN and SCC require wide excisional biopsy with $4 \mathrm{~mm}$ margins followed by cryotherapy to the resected edges [8]. Nevus is a benign growth and excisional biopsy is performed with $2 \mathrm{~mm}$ wide margins [4]. PAM and melanoma also require a $4 \mathrm{~mm}$ wide margin excisional biopsy and cryotherapy to the resected edges $[5,6,9]$. Lymphoid tumors are treated by excisional biopsy and cryotherapy for smaller tumors, and incisional biopsy followed by chemotherapy and radiotherapy for larger tumors $[10,11]$. Caruncular tumors are always managed by complete surgical excision with an appropriate margin on the conjunctival edge $[12,13]$.

\section{Surgical Techniques}

Conjunctival tumor excision can be performed under local anesthesia. This is achieved by $5 \mathrm{~mL}$ of retrobulbar injection of a combination of $2 \%$ bupivacaine and $0.75 \%$ of mepivacaine with hyaluronidase into the retrobulbar space. The injection is given using a 1.25 inch $27 \mathrm{G}$ needle attached to a $5 \mathrm{~mL}$ syringe. A well-performed retrobulbar block eliminates pain sensation, prevents ocular motility, and does not produce any conjunctival chemosis. We specifically avoid subconjunctival anesthesia as this balloons the conjunctiva and blurs tumor margins. It is important to prevent chemosis to help identify the anatomical landmarks and tumor margins during the surgery. An eyelid speculum is applied and topical anesthesia used for the cornea. The surgery is always done under an operating microscope.

Surgical steps for benign and malignant tumors are similar, except for the need for wider surgical margins for malignant tumors, and a thin scleral base. Wide excision of the lesion (4 $\mathrm{mm}$ surgical margin) is the standard care of treatment for malignant conjunctival tumors including invasive SCC (Fig. 7.1a-i and Video 7.1) and malignant melanoma (Fig. 7.2a-l and Video 7.2). In contrast, a 1-2 mm surgical margin is adequate for conjunctival nevus (Fig. 7.3a-i and Video 7.3) and PAM (Fig. 7.4a-h and Video 7.4). The corneal component is identified and the site is gently patted - dry with a single movement without rubbing and with a dry cellulose sponge. Absolute alcohol (ethyl alcohol-ETOH) is applied directly to the affected cornea using a wexcel sponge for 10-20 s and then a second dry sponge absorbs the alcohol to prevent damage $[14,15]$. This is done to devitalize the corneal tumor cells. The corneal tumor is removed off the cornea by gently scrolling the epithelium from center to limbus using a \#57 Beaver scalpel and this is termed as alcohol keratoepitheliectomy. The plane of dissection is kept anterior to the Bowman's membrane so as to not cause corneal scarring. The scrolled tissue is left at the limbus in a dry fashion. Next, a $4 \mathrm{~mm}$ wide surgical margin around the conjunctival component is marked using a bipolar cautery. Minimum manipulation is 

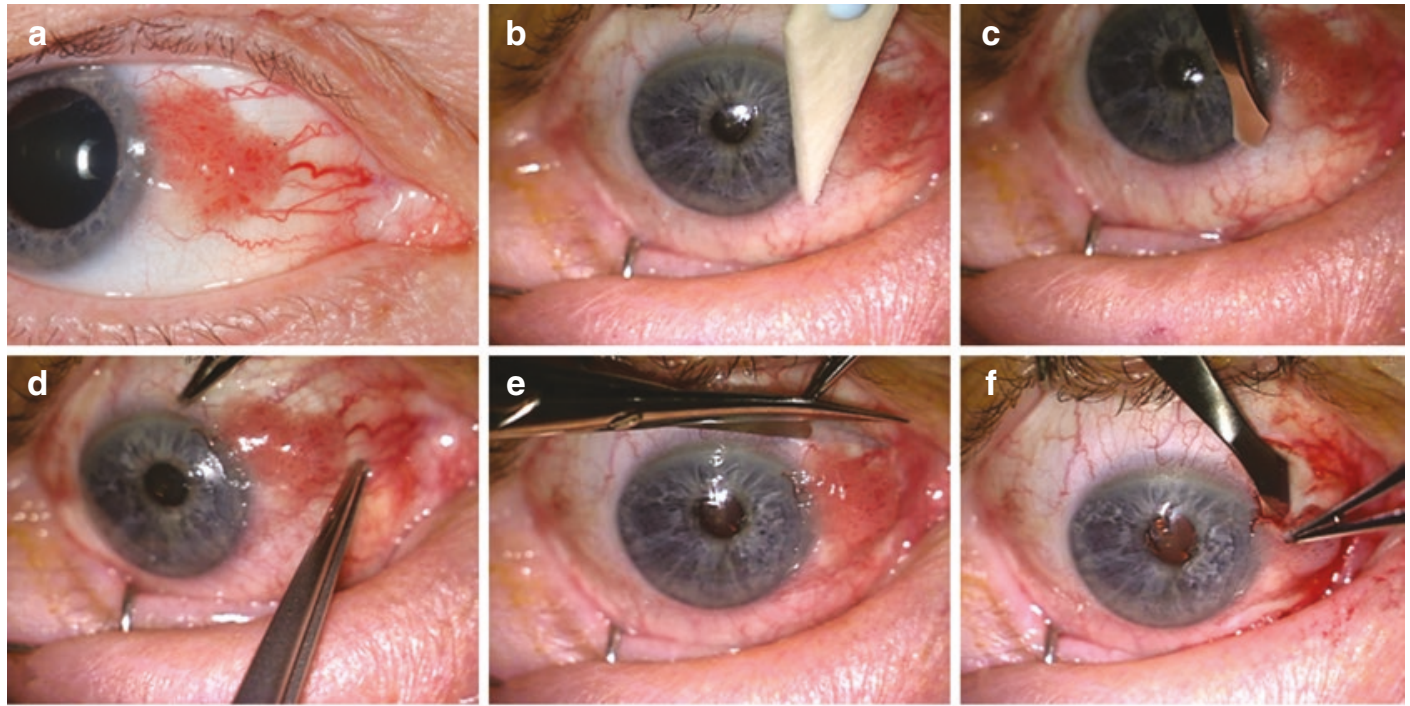
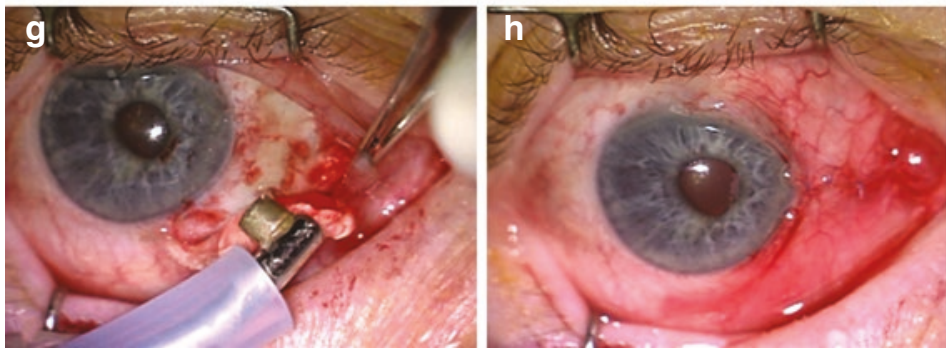

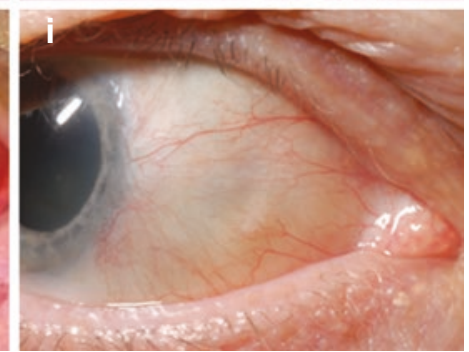

Fig. 7.1 Excision surgery for conjunctival squamous cell carcinoma. (a) Conjunctival squamous cell carcinoma of the left eye with prominent feeder and intrinsic vessels. (b) Corneal component of the tumor is identified and dried with a dry cellulose sponge, followed by application of absolute alcohol using a cotton-tipped applicator for $1 \mathrm{~min}$. (c) Corneal tumor is excised off the cornea by gently scrolling away the epithelium using a \#57 Beaver scalpel, with the plane of dissection maintained anterior to the Bowman's membrane. (d) Prominent feeder vessels are identified and cauterized to minimize bleeding. (e) The conjunctiva is incised with a 4-mm-wide surgical margin using a blunt-tipped conjunctival scissors. (f) At the limbus, limbectomy is done parallel to the limbus by sliding the blade back and forth, thus completely excising the tumor with a thin scleral base. (g) Double freeze-thaw cryotherapy is done to the resected edges of the conjunctiva by lifting the conjunctiva with forceps and freezing the underside of the conjunctiva to prevent accidental freezing of the sclera or the ciliary body. (h) Conjunctival closure is done using a 7-0 absorbable suture. (i) Minimal conjunctival scarring with no recurrence at 6 months follow-up

sors. Similar undermining of the Tenon's fascia is undertaken by gentle spreading of the scissors. In tumors where dissection is close to the insertion of the rectus muscles, the muscles may be hooked to avoid damage to the muscle fibers. Hemostasis is achieved with the use of bipolar cautery.

The scleral component of the tumor is removed using a clean \#57 Beaver scalpel and a few underlying scleral fibers (5\% thickness) are dissected with the mass to provide tumor-free basal margin $[14,15]$. This is termed partial scleroconjunctivectomy. The sclerolimbectomy is done with the from the tissues below with the help of the scis- 

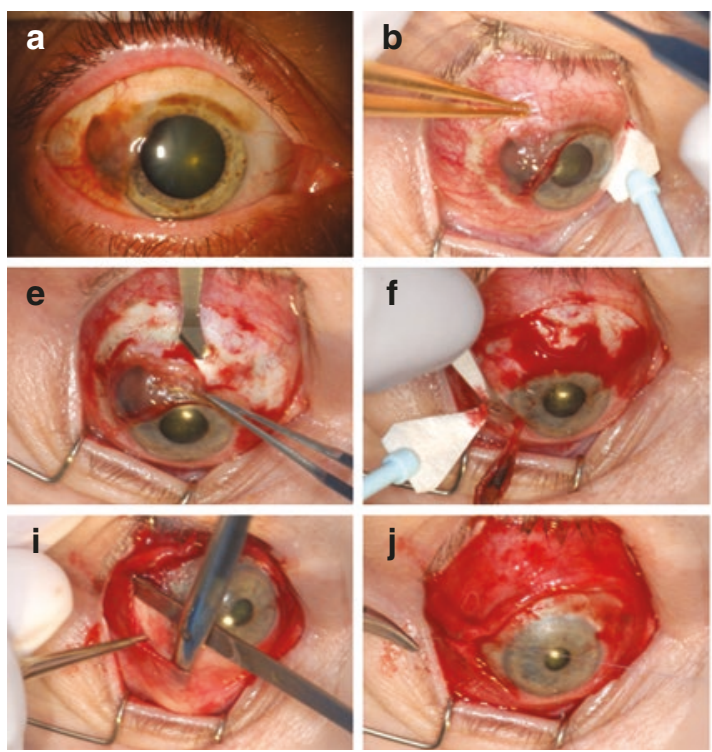

Fig. 7.2 Excision surgery for conjunctival melanoma. (a) Conjunctival melanoma of the right eye with dark pigmentation and prominent feeder vessels. (b) A 4-mmwide surgical margin is delineated around the tumor using bipolar cautery, and the corneal component of the tumor is identified and dried with a dry cellulose sponge, followed by application of absolute alcohol using a cotton-tipped applicator for $1 \mathrm{~min}$. (c) The limbal conjunctiva is lifted using a forceps, and a small incision placed in the conjunctiva at one end of the marked surgical margin using a blunt-tipped conjunctival scissors. (d) The conjunctiva is incised along the marked margin. (e) Corneal tumor is excised off the cornea by gently scrolling away the epithelium using a \#57 Beaver scalpel, with the plane of dissection maintained anterior to the Bowman's membrane.

flat blade parallel to the limbus with the motion of the blade from the cornea toward the sclera, thus completely excising the tumor with a thin scleral base. Through all these steps of the surgery, use of BSS on the ocular surface is avoided, and this is the dry-technique of tumor excision. The tumor is labeled indicating all the margins on a cardboard bed, preserved in $10 \%$ formalin, and sent for histopathology ensuring the correct patient identity on the pathology form.

For further steps of the surgery, a fresh set of instruments is used to prevent any possible tumor seeding from the previous instruments. Episcleral hemostasis is achieved with bipolar cautery. Absolute alcohol is then applied over the bare sclera using a wexcel sponge to devitalize any remaining tumor cell on the scleral surface
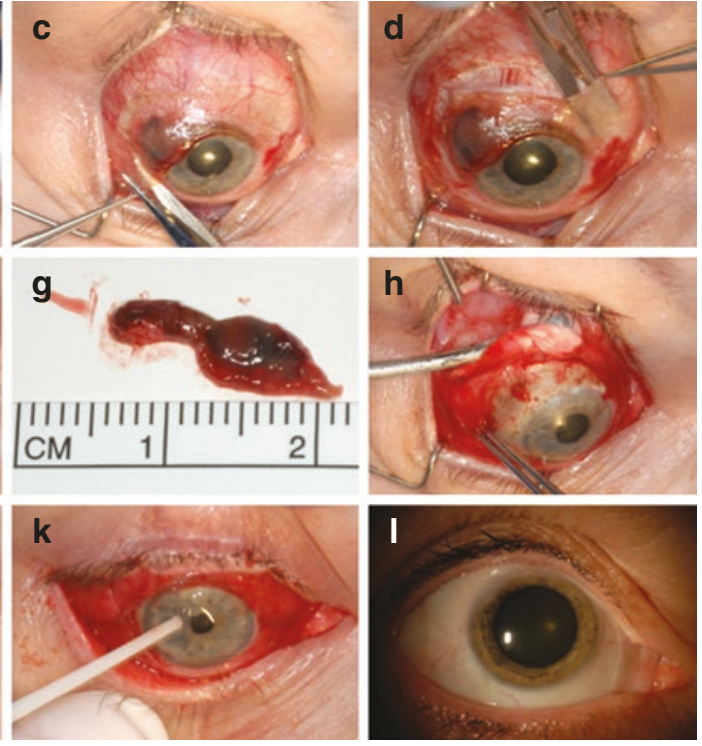

(f) At the limbus, limbectomy is done parallel to the limbus by sliding the blade back and forth, thus completely excising the tumor with a thin scleral base. (g) The excised tumor is placed on a cardboard and placed in 10\% formalin for histopathology. (h) Double freeze-thaw cryotherapy is done to the resected edges of the conjunctiva by lifting the conjunctiva with forceps and freezing the underside of the conjunctiva to prevent accidental freezing of the sclera or the ciliary body. (i) Conjunctival relaxation is achieved by excising the intermuscular septum. (j) Conjunctival closure is done using a 7-0 absorbable suture. (k) Application of tissue glue on the ocular surface for patient comfort and better wound healing. (l) Minimal conjunctival and corneal scarring with no recurrence at 9 months follow-up

then with a \#57 beaver blade the episcleral debris is swept onto a wexcel sponge.

Double freeze-thaw cryotherapy is done to the resected conjunctiva edges. This is done by lifting the conjunctiva with Bishop-Harmon forceps and freezing the underside of the conjunctiva to prevent accidental freezing of the sclera or the ciliary body. A dense ice ball formation for $10 \mathrm{~s}$ is allowed before slow thawing is done. There is no BSS used for defrosting. The probe is shifted to an adjacent spot such that two adjacent frozen spots overlap slightly to prevent any untreated area. The entire margin is frozen in a freezedefrost, freeze-defrost fashion (double freezethaw). Conjunctival closure is done in two layers with Tenon's fascia deep and conjunctiva superficial or with a superficial graft as described below. 

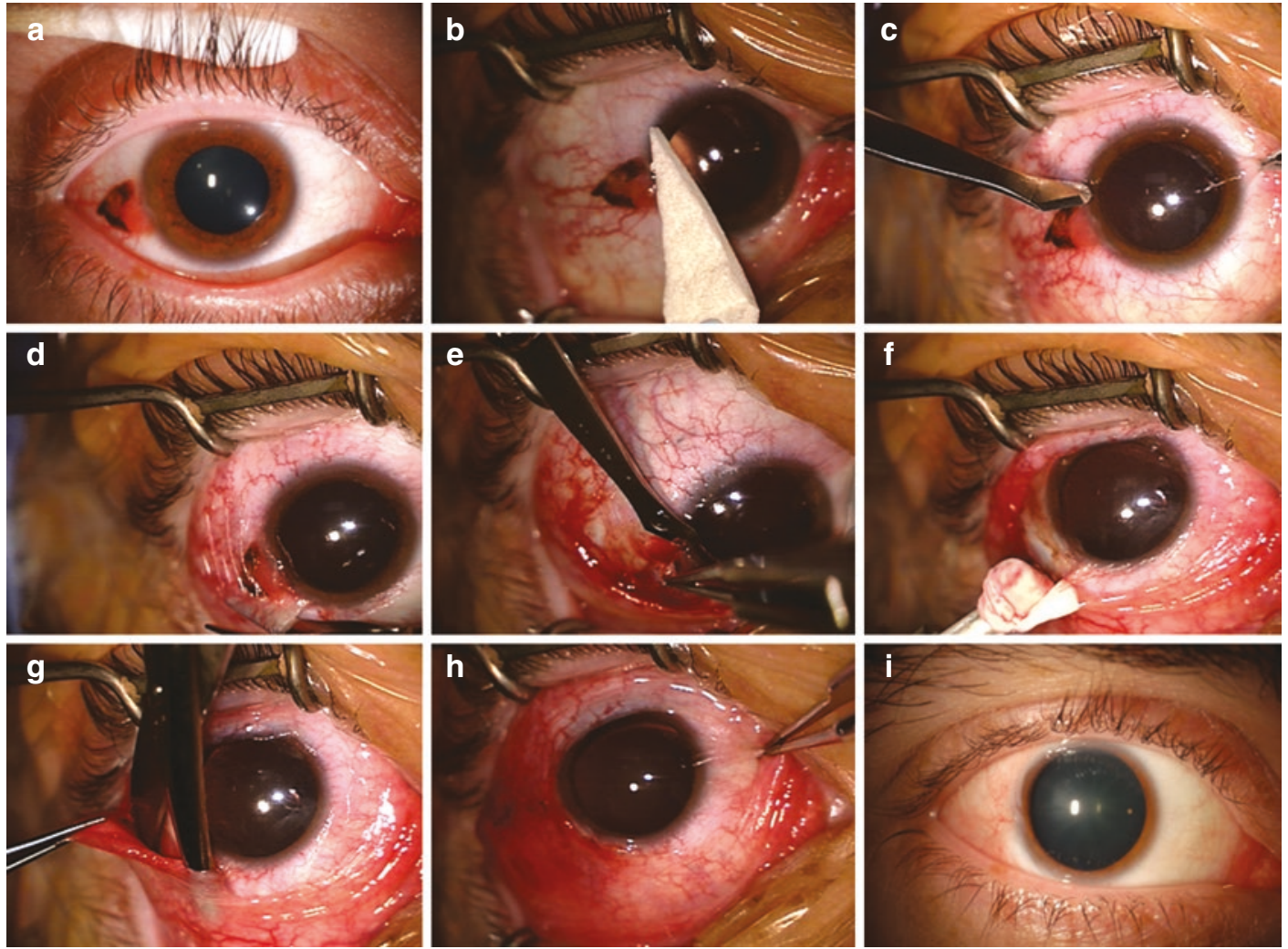

Fig. 7.3 Excision surgery for conjunctival nevus. (a) Conjunctival nevus of the right eye with melanotic and amelanotic components. (b) Corneal tumor is identified and dried with a dry cellulose sponge, followed by application of absolute alcohol using a cotton-tipped applicator for $1 \mathrm{~min}$. (c) Corneal tumor is excised off the cornea by gently scrolling away the epithelium using a \#57 Beaver scalpel, with the plane of dissection maintained anterior to the Bowman's membrane. (d) The conjunctiva is incised with a $2 \mathrm{~mm}$ wide surgical margin using a blunt-tipped conjunctival scissors. (e) At the limbus, limbectomy is

Caruncular tumors can also be excised in a similar fashion. Medial rectus muscle hooking is necessary in larger tumors. However, unlike at other sites, it is not possible to obtain a $4 \mathrm{~mm}$ margin around the tumor of the caruncle.

Post-operative care involves patching of the eye for 2 days with cycloplegic drops and antibiotic-steroid ointment. Use of the ointment twice daily for 3 weeks is advised. Patient is generally seen in a month after the surgery by which time the pathology report is available and the patient can be counseled regarding the final histopathologic diagnosis. In done parallel to the limbus by sliding the blade back and forth, thus completely excising the tumor with a thin scleral base. (f) Double freeze-thaw cryotherapy is done to the resected edges of the conjunctiva by lifting the conjunctiva with forceps and freezing the underside of the conjunctiva to prevent accidental freezing of the sclera or the ciliary body. (g) Conjunctival relaxation is achieved by excising the intermuscular septum. (h) Conjunctival closure is done using a 7-0 absorbable suture. (i) Minimal conjunctival scarring with no recurrence at 5 months follow-up

invasive SCC, if the surgical margins are positive, topical immunotherapy (preferred over topical chemotherapy) is advised for 3 months. Radiotherapy in the form of surface plaque brachytherapy is gaining popularity for recurrent tumors and for tumors with deeper scleral invasion [2, 3]. For conjunctival melanoma, if the margins are positive, repeat surgery for clear margins is done. The patient can then be followed-up every 3 months for 1 year, every 6 months for 3 years, and yearly thereafter. The follow-up intervals can be extended for patients with benign tumors. 

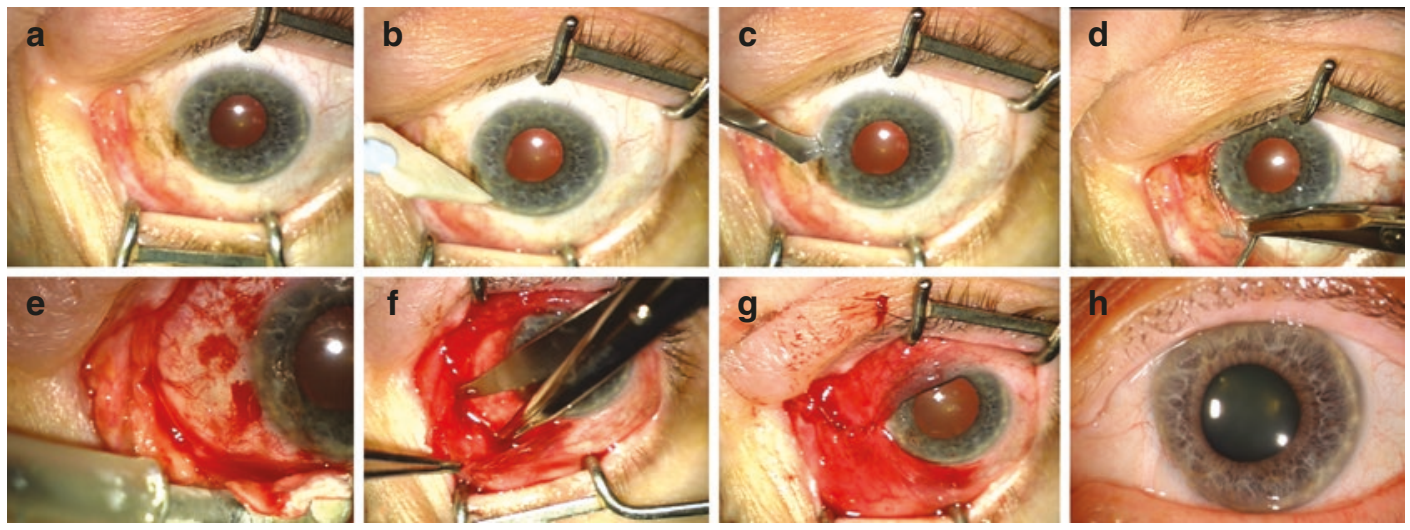

Fig. 7.4 Excision surgery for conjunctival primary acquired melanosis. (a) Conjunctival primary acquired melanosis of the left eye. (b) Corneal component of the tumor is identified and dried with a dry cellulose sponge, followed by application of absolute alcohol using a cotton-tipped applicator for $1 \mathrm{~min}$. (c) Corneal tumor is excised off the cornea by gently scrolling away the epithelium using a \#57 Beaver scalpel, with the plane of dissection maintained anterior to the Bowman's membrane. (d) The conjunctiva is incised with a 2 -mm-wide surgical

\section{Ocular Surface Reconstruction}

Conjunctival reconstruction is done by conjunctival advancement, rotational, and flap or with the use of amniotic membrane grafts (AMGs). Advancement flap involves sliding of the conjunctiva to cover the bare sclera. This is done by creating a peritomy at the limbus for $4-5 \mathrm{~mm}$ so that the conjunctiva can be mobilized over the defect. The conjunctiva is then closed with 7-0 Vicryl sutures in a running or an interrupted fashion in 2 layers (Tenon's fascia and conjunctiva). For larger conjunctival defects which cannot be closed by an advancement flap, a rotational flap or an AMG can be placed over the bare sclera. The rotational flap is derived generally from the superotemporal fornix and rotated into the defect. The AMG can be freeze-dried or frozen type and is anchored on the surface with the use of tissue glue alone, or by cardinal suturing it to the conjunctiva with 7-0 absorbable sutures. AMG is a source of stem cells and provides a surface over which conjunctivalization can take place $[16,17]$. A recently popularized method for stem cell harvest is excision of a $2 \times 2 \mathrm{~mm}$ area of the superior limbal tissue and cutting it into 8-10 margin using a blunt-tipped conjunctival scissors. (e) Double freeze-thaw cryotherapy is done to the resected edges of the conjunctiva by lifting the conjunctiva with forceps and freezing the underside of the conjunctiva to prevent accidental freezing of the sclera or the ciliary body. (f) Conjunctival relaxation is achieved by excising the intermuscular septum. (g) Conjunctival closure is done using a 7-0 absorbable suture. (h) Minimal conjunctival scarring with no recurrence at 4-month follow-up

pieces $[18,19]$. These small limbal transplants are placed on the AMG, and fixed with tissue glue $[18,19]$. This is known as the simple limbal epithelial transplantation (SLET).

\section{Conjunctival Map Biopsy}

Conjunctival map biopsies are performed for extensive conjunctival tumors or those that have invaded from adjacent structures, like sebaceous carcinoma. Sebaceous carcinoma has a tendency to exhibit diffuse involvement in the conjunctiva, known as the pagetoid spread (intraepithelial involvement). Small map biopsies are useful to determine the extent of the disease and to plan definitive treatment. The surgery is performed under local anesthesia using retrobulbar block as described above.

Routinely, 10-14 biopsies are taken depending on the suspected area of conjunctival involvement [20]. To gain good surgical access to the deeper fornix, the lids can be everted over a Desmarre's retractor or a simple Q-tip. The map biopsies must include both surface epithelium and tarsal tissue (or the stroma in the bulbar conjunctiva). Each biopsy is approximately $2 \mathrm{~mm}$ in basal diameter 
$[21,22]$. The areas of map biopsies includes superior tarsus $(n=2)$, inferior tarsus $(n=2)$, and all four quadrants on the bulbar conjunctiva $(n=4$ or more) [21, 22]. If possible, central tarsus biopsy is avoided to prevent scarring that could lead to corneal erosion. If clinically limbal or corneal involvement is suspected, then limbal conjunctival biopsies $(n=4)$ are taken at superior, medial, inferior, and temporal limbus. Each of the specimens is carefully labeled and numbered on a large diagram for histopathologic study. The small map biopsy specimens should be submitted for permanent sections rather than frozen sections.

Once the permanent histopathologic results are obtained, then the definitive surgery can be undertaken after 3 weeks. The need for repeat map biopsies in a patient depends on the clinical findings during follow-up. Double freeze-thaw cryotherapy is done to most of the bulbar and palpebral conjunctiva to provide further assurance that microscopic intraepithelial involvement by the tumor is adequately treated [20].

In conclusion, a variety of benign and conjunctival tumors are seen in children and adults. A basic understanding of the biological behavior of the tumor is pertinent in planning its management. Not all conjunctival tumors require surgery. However, when a surgery is planned, the application of a protocol-based surgical technique can achieve a high cure rate. In addition, the use of adjunctive treatment including topical and locally injectable chemotherapy and immunotherapy, and surface application of plaque radiotherapy have rendered most conjunctival tumors eminently curable.

\section{References}

1. Kaliki S, Arepalli S, Shields CL, et al. Conjunctival papilloma: features and outcomes based on age at initial examination. JAMA Ophthalmol. 2013;131(5):585-93.

2. Walsh-Conway N, Conway RM. Plaque brachytherapy for the management of ocular surface malignancies with corneoscleral invasion. Clin Exp Ophthalmol. 2009;37(6):577-83.

3. Arepalli S, Kaliki S, Shields CL, Emrich J, Komarnicky L, Shields JA. Plaque radiotherapy in the management of scleral-invasive conjunctival squamous cell carcinoma: an analysis of 15 eyes. JAMA Ophthalmol. 2014;132(6):691-6.
4. Shields CL, Fasiudden A, Mashayekhi A, et al. Conjunctival nevi: clinical features and natural course in 410 consecutive patients. Arch Ophthalmol. 2004;122:167-75.

5. Shields JA, Shields CL, Mashayekhi A, et al. Primary acquired melanosis of the conjunctiva: risks for progression to melanoma in 311 eyes. The 2006 Lorenz E. Zimmerman lecture. Ophthalmology. 2008;115(3):511-9.

6. Shields CL, Markowitz JS, Belinsky I, et al. Conjunctival melanoma: outcomes based on tumor origin in 382 consecutive cases. Ophthalmology. 2011;118(2):389-95.e1-2.

7. Shields J, Shields C. Conjunctival and epibulbar choristomas. In: Shields J, Shields C, editors. Atlas of eyelid, conjunctival and orbital tumors. 3ed ed. Philadelphia: Lippinoctt, Wolters Kluwer; 2016. p. 251-66.

8. Lee GA, Hirst LW. Ocular surface squamous neoplasia. Surv Ophthalmol. 1995;39:429-50.

9. Folberg R, McLean IW, Zimmerman LE. Primary acquired melanosis of the conjunctiva. Hum Pathol. 1985;16(2):129-35.

10. Kirkegaard MM, Rasmussen PK, Coupland SE, et al. Conjunctival lymphoma-an international multicenter retrospective study. JAMA Ophthalmol. 2016;134(4):406-14.

11. Shields CL, Shields JA, Carvalho C, et al. Conjunctival lymphoid tumors: clinical analysis of 117 cases and relationship to systemic lymphoma. Ophthalmology. 2001;108(5):979-84.

12. Shields CL, Shields JA, White D, et al. Types and frequency of lesions of the caruncle. Am J Ophthalmol. 1986;102:771-8.

13. Shields J, Shields C. Caruncular tumos. In: Shields J, Shields C, editors. Atlas of eyelid, conjunctival and orbital tumors. 3ed ed. Philadelphia: Lippinoctt, Wolters Kluwer; 2016. p. 394-402.

14. Shields JA, Shields CL, De Potter P. Surgical management of circumscribed conjunctival melanomas. Ophthal Plast Reconstr Surg. 1998;14(3):208-15.

15. Shields JA, Shields CL, De Potter P. Surgical management of conjunctival tumors. The 1994 Lynn B. McMahan lecture. Arch Ophthalmol. 1997;115(6):808-15.

16. Tejwani S, Kolari RS, Sangwan VS, Rao GN. Role of amniotic membrane graft for ocular chemical and thermal injuries. Cornea. 2007;26(1):21-6.

17. Paridaens D, Beekhuis H, van Den Bosch W, et al. Amniotic membrane transplantation in the management of conjunctival malignant melanoma and primary acquired melanosis with atypia. $\mathrm{Br} \mathrm{J}$ Ophthalmol. 2001;85(6):658-61.

18. Sangwan VS, Basu S, MacNeil S, Balasubramanian D. Simple limbal epithelial transplantation (SLET): a novel surgical technique for the treatment of unilateral limbal stem cell deficiency. Br J Ophthalmol. 2012;96(7):931-4.

19. Vazirani J, Basu S, Kenia H, et al. Unilateral partial limbal stem cell deficiency: contralateral versus ipsilateral autologous cultivated limbal epithelial transplantation. Am J Ophthalmol. 2014;157(3):584-90.e1-2. 
20. Shields JA, Saktanasate J, Lally SE, et al. Sebaceous carcinoma of the ocular region: the 2014 Professor Winifred Mao lecture. Asia Pac J Ophthalmol (Phila). 2015;4(4):221-7.

21. Shields JA, Demirci H, Marr BP, Eagle RC Jr, Stefanyszyn M, Shields CL. Conjunctival epithelial involvement by eyelid sebaceous carcinoma. The 2003 J.Howard Stokes lecture. Ophthal Plast Reconstr Surg. 2005;21(2):92-6.

22. Putterman AM. Conjunctival map biopsy to determine pagetoid spread. Am J Ophthalmol. 1986;102(1):87-90.

Open Access This chapter is licensed under the terms of the Creative Commons Attribution 4.0 International License (http://creativecommons.org/licenses/by/4.0/), which permits use, sharing, adaptation, distribution and reproduction in any medium or format, as long as you give appropriate credit to the original author(s) and the source, provide a link to the Creative Commons license and indicate if changes were made.

The images or other third party material in this chapter are included in the chapter's Creative Commons license, unless indicated otherwise in a credit line to the material. If material is not included in the chapter's Creative Commons license and your intended use is not permitted by statutory regulation or exceeds the permitted use, you will need to obtain permission directly from the copyright holder. 